\title{
Characteristics of Asthma Resistant to Moderate Dose Inhaled Corticosteroid Treatment on Bronchial Hyperresponsiveness
}

\author{
Keisaku Fujimoto ${ }^{1}$, Shinji Yamaguchi ${ }^{1}$, Kazuhisa Urushibata ${ }^{1}$, Masayuki Hanaoka ${ }^{1}$, \\ Tomonobu Koizumi ${ }^{1}$, Takayuki Honda ${ }^{2}$ and Keishi Kubo ${ }^{1}$
}

\begin{abstract}
Object This study was performed to determine the clinical characteristics of asthmatics with bronchial hyperresponsiveness (BHR) that could not be normalized by 6 months of treatment with a moderate dose of an inhaled corticosteroid (ICS).

Methods Thirty-four symptomatic patients with mild to moderate asthma, who had never received any ICS, were treated with $200 \mu \mathrm{g}$ of inhaled fluticasone propionate twice a day for 6 months. Spirometry, BHR to methacholine, exhaled nitric oxide (NO) and eosinophils in induced sputum were examined before and 2 and 6 months after beginning treatment.

Results $\mathrm{FEV}_{1}$ was increased and bronchial responsiveness, exhaled NO and sputum eosinophilia were significantly decreased 2 and 6 months after starting ICS treatment. Bronchial responsiveness was further decreased at 6 months together with a further increase in $\mathrm{FEV}_{1}$. In 13 patients, BHR was not normalized despite the 6 months of treatment. This group showed a higher prevalence of males, those with a smoking history and airflow limitation, a higher eosinophil count in the sputum following 6 months of treatment and a longer history of asthma. Multiple, stepwise, linear regression analysis showed that sputum eosinophilia and lower $\mathrm{FEV}_{\mathrm{l}} / \mathrm{FVC}$ following 6 months of treatment and a longer history of asthma were significant independent determinants for BHR after 6 months of ICS treatment.

Conclusions These findings suggest that the resistance to a moderate dose of ICS for BHR in asthmatics may be significantly associated with remained airflow limitation, eosinophilic airway inflammation resistive to moderate dose of ICS, and delayed introduction of ICS therapy.
\end{abstract}

Key words: asthma, inhaled corticosteroid (ICS), exhaled nitric oxide, eosinophilic airway inflammation, bronchial hyperresponsiveness (BHR)

(DOI: 10.2169/internalmedicine.45.1749)

\section{Introduction}

Chronic allergic airway inflammation is the major cause of the symptoms and bronchial hyperresponsiveness (BHR) in asthma, even in mild cases (1). Such inflammation may lead to changes in airway structure, causing irreversible airflow limitation and persistent symptoms $(2,3)$. Inhaled corticosteroids (ICS) decrease the airway inflammation, im- prove lung function, lessen symptoms and BHR and reduce mortality (4-6). Therefore, ICS is considered the first line of treatment in asthma.

In 1994, Haahtela et al (7) reported that early intervention with ICS in newly diagnosed asthmatic adults improves the prognosis of asthma. They compared two groups of newly diagnosed asthma patients treated with 1,200 $\mu \mathrm{g} / \mathrm{day}$ of inhaled budesonide for two years followed by $400 \mu \mathrm{g} / \mathrm{day}$ of inhaled budesonide at the beginning of a three-year study or

\footnotetext{
${ }^{1}$ First Department of Internal Medicine, Shinshu University School of Medicine, Matsumoto and ${ }^{2}$ Department of Laboratory Medicine, Shinshu University School of Medicine, Matsumoto

Received for publication February 2, 2006; Accepted for publication May 11, 2006

Correspondence to Keisaku Fujimoto, First Department of Internal Medicine, Shinshu University School of Medicine, 3-1-1 Asahi, Matsumoto $390-8621$
} 
with terbutaline for two years followed by $1,200 \mu \mathrm{g} / \mathrm{day}$ of inhaled budesonide. The degrees of improvement in lung function and bronchial responsiveness to histamine and asthma control were less in patients with delayed budesonide treatment as compared with those treated with budesonide at the beginning of the three-year study. Early treatment with inhaled budesonide resulted in long-lasting control of mild asthma. In a recent a 3-year study in patients with recent onset mild persistent asthma, early once-daily treatment with low-dose budesonide (400 $\mu \mathrm{g} /$ day) also reduced the risk of severe asthma exacerbation by almost half, and resulted in more symptom-free days and a reduced need for courses of systemic corticosteroids and additional treatment for asthma (8). This report provided evidence on which to base recommendations for treatment regarding the use of ICS in mild persistent asthma (9).

The present study was performed to examine whether early intervention with $200 \mu \mathrm{g}$ of inhaled fluticasone propionate (FP) twice a day for 6 months can improve BHR to methacholine together with improvement of allergic airway inflammation in adult patients with mild to moderate asthma that had not ever been treated with any ICS from the onset of asthma. We also examined the characteristics of asthmatic patients whose BHR did not improve despite 6 months of treatment with a moderate dose of inhaled FP. As an index of allergic airway inflammation, we examined eosinophilia in induced sputum and measured the concentration of exhaled nitric oxide (NO). Exhaled NO has been proposed as a non-invasive marker of airway inflammation in asthma (10), and it has been demonstrated that there are relationships between exhaled $\mathrm{NO}$ and markers of mucosal eosinophilic inflammation in asthma (11). Jones et al (12) reported that exhaled NO measurements were as useful as induced sputum analysis and BHR in assessing airway inflammation and predicting loss of control in asthma following steroid withdrawal. Exhaled NO may be a useful indicator in the longitudinal assessment of asthma control.

\section{Materials and Methods}

\section{Subjects}

Forty-two symptomatic patients with mild to moderate bronchial asthma, who had never received treatment with any ICS from the onset of asthma, were recruited from our outpatient clinic. Asthma was defined as a clinical history of intermittent wheeze, cough, chest tightness, or dyspnea, documented reversible airflow limitation either spontaneously or with treatment with an inhaled $\beta_{2}$-agonist and BHR to methacholine. Among the 42 patients initially enrolled, 34 completed the study. The remaining 8 patients dropped out during the study because of the administration of systemic corticosteroids and/or with an add-on leukotriene receptor A antagonist (LTRA) and/or a long-acting $\beta_{2}$-agonist (LABA) due to exacerbation (5 patients) and no admission to hospital or no adequate sputum sample obtained (3 patients). Ta-
Table 1. Characteristics of the 34 Patients with Asthma

\begin{tabular}{lc}
\hline Age, yr & $48.4 \pm 2.9$ \\
Sex (males/females) & $20 / 14$ \\
Smoking history, $\mathrm{n}$ & 16 \\
Severity (step 1/2/3), $\mathrm{n}$ & $4 / 13 / 17$ \\
Duration of illness, months & $42.7 \pm 9.7$ \\
VC, \% of pred. & $106.1 \pm 2.5$ \\
FEV,$\%$ of pred. & $85.5 \pm 2.8$ \\
FEV,/FVC, \% & $76.2 \pm 2.3$ \\
DLco, \% of pred. & $100.0 \pm 3.0$ \\
Induced sputum & \\
Total cells, x10 $/ \mathrm{g}$ & $158.9 \pm 64.8$ \\
Macrophage, \% & $18.1 \pm 2.9$ \\
Lymphocyte, \% & $5.6 \pm 0.8$ \\
Neutrophil, \% & $56.1 \pm 4.8$ \\
Eosinophil, \% & $20.5 \pm 3.9$ \\
Exhaled nitric oxide, ppb & $166.6 \pm 22.2$ \\
Dmin, U & $2.1 \pm 0.4$ \\
\hline
\end{tabular}

Values are means \pm SEM.

ble 1 shows the characteristics of the 34 patients. The patients ranged in age from 15 to 74 years, with a mean of $48.4 \pm 2.9$ years. Five patients were current smokers, and 11 were former smokers. In accordance with the Global Initiative for Asthma (GINA) guidelines (9), the patients were classified as follows: intermittent mild asthma, 4 patients; persistent mild asthma, 13 patients; and moderate persistent asthma, 17 patients. The durations of asthma histories were from 2 to 228 months, with a mean of $42.7 \pm 9.7$ months. All asthmatic patients were taking an inhaled $\beta_{2}$-agonist when needed. The patients with intermittent mild asthma were treated only with an inhaled $\beta_{2}$-agonist when needed. Of patients with persistent mild asthma, 7 were taking no treatment and 6 were treated with oral theophylline and/or a long-acting inhaled $\beta_{2}$ agonist (LABA). All patients with moderate persistent asthma were taking oral theophylline and/or LABA and/or LTRA. All patients were free from airway infections for 1 month prior to the study. All subjects gave informed consent to participation in the study, which had the approval of the hospital's ethical committee.

\section{Study design}

Symptomatic adult patients with mild to moderate asthma from our outpatient clinic, who had not been treated with any ICS from the onset of asthma, were enrolled in the study. At initial consultation, each patient underwent a standard clinical assessment, which consisted of a history and physical examination and completion of a medical questionnaire, laboratory tests, including the measurement of serum total $\operatorname{IgE}$ and $\operatorname{IgE}$ radioallergosorbent test (RAST) to 26 common allergens, chest radiography and pulmonary function tests (Chestac-55V; Chest Co., Ltd., Tokyo, Japan). At the second visit, the concentration of exhaled NO was measured, and then the bronchial responsiveness to methacholine 
was examined. The following day, sputum was collected following induction with hypertonic saline. After completion of baseline measurements, all patients were treated with $200 \mu \mathrm{g}$ of inhaled fluticasone propionate (FP) twice a day in addition to their previous treatment regimen. Exhaled NO, spirometry and bronchial responsiveness were again measured in all patients, and their induced-sputum was obtained at 2 and 6 months after the start of ICS.

\section{Bronchial responsiveness to methacholine}

Bronchial responsiveness was estimated using the continuous methacholine inhalation method combined with simultaneous measurement of respiratory resistance $\left(R \mathrm{rs} ; \mathrm{cmH}_{2} \mathrm{O} / \mathrm{L} /\right.$ s) using the device developed by Takishima et al (13) (Astograph; Chest, Tokyo, Japan). Briefly, methacholine chloride (Daiichi Kagaku Yakuhin Co., Tokyo, Japan) diluted with physiological saline was inhaled during tidal breathing from a nebuliser in 10 steps at concentrations that doubled at every step (from $49 \mu \mathrm{g} / \mathrm{ml}$ to $25 \mathrm{mg} / \mathrm{ml}$ ). After recording the baseline Rrs during inhalation of physiological saline for 1 min, inhalation of methacholine chloride was performed at 1-min intervals until the Rrs reached approximately twice the baseline value, or until the maximum concentration had been administered. The cumulative dose of inhaled methacholine at the inflection point where Rrs began to increase (Dmin) was adopted as the marker for bronchial responsiveness. This parameter was measured in terms of a unit defined as $1-\mathrm{min}$ inhalation of $1 \mathrm{mg} / \mathrm{ml}$ methacholine. The total cumulative dose of methacholine at inhalation of the maximum dose $(25 \mathrm{mg} / \mathrm{ml})$ was 50 units. AHR was defined as $D \min \leq 12.5 \mathrm{U}(13,14)$.

\section{Sputum collection and analysis}

We collected sputum induced by inhalation of hypertonic saline as described previously (15). The method of sputum induction was as follows: prior to the induction of sputum, all subjects inhaled a $\beta_{2}$-agonist, and $3.5 \%$ hypertonic saline was nebulized with an ultrasonic nebulizer (NE-V10B; Omron, Tokyo, Japan) for a period of $10 \mathrm{~min}$. If the appropriate sputum could not be obtained, $4.5 \%$ hypertonic saline was nebulized for periods of $5 \mathrm{~min}$. Nebulization was discontinued if the $\mathrm{FEV}_{1}$ decreased by more than $20 \%$ or if problematic symptoms occurred. The nebulization was continued for at least 10 minutes and stopped after 15 minutes or if a good quality sputum sample of $\geq 2 \mathrm{ml}$ was obtained. For collection of induced sputum, the subjects were asked to rinse their mouths and throats and then to try to cough up sputum into a sterile plastic dish. The sputum was then separated from contaminating saliva by macroscopic examination, and the mucus plug was removed from the dish onto a sterile plastic container, after which the volume of the sample was determined. The sample was overlaid with an equal volume of Hank's balanced salt solution (HBSS) containing $1 \mathrm{mM}$ dithiothreitol (Sigma Chemicals, Poole, UK) and incubated at $37^{\circ} \mathrm{C}$ for 15 minutes. The incubated suspension was then washed twice with HBSS. After the resid- ual mucous was removed by filtering the suspension with gauze, the eluent was used for total and differential cell counts. The total cell count, except that of squamous cells, was determined with a standard hemocytometer, normalized for weight and expressed as number of cells $\times 10^{5} / \mathrm{g}$ wet weight of sputum. Cell smears were prepared by centrifugation (Autosmear; Sakura, Tokyo, Japan) and stained with May-Grünwald-Giemsa stain for differential cell counting, which was carried out in a blinded fashion. The slides were coded and 500 cells were counted for differential leukocyte counting. The results of the differential leukocyte counts were expressed as percentages of nucleated cells except for squamous and epithelial cells.

\section{Measurement of exhaled nitric oxide}

Fractional exhaled NO concentration was measured using a chemiluminescence analyzer (CLM-500; Shimadzu, Kyoto, Japan) calibrated with a certified NO calibration gas mixture as described previously $(16,17)$. The analyzer was sensitive to NO levels as low as 2 parts per billion (ppb), with a response time of less than $200 \mathrm{~ms}$, and was adapted for online recording of NO concentrations. The analyzer sample flow rate was kept constant at $600 \mathrm{ml} / \mathrm{min}$. Each subject was seated comfortably and NO was sampled via a mouthpiece without the use of a nose clip. Following deep breathing by mouth, each of the subjects inhaled NO-free gas, also via the mouth, to their total achievable lung capacity followed by slow exhalation. The online single exhalation technique with an exhalation rate of $2 \mathrm{~L} / \mathrm{min}$ and positive expiratory mouth pressure of $8 \sim 10 \mathrm{cmH}_{2} \mathrm{O}$ was applied, according to the recommendations of ATS (17). The mean exhaled NO concentration of three acceptable end-expiratory plateau measurements was calculated.

\section{Data analysis}

The values shown in the text, figures and tables are means \pm SEM. Comparison of variables at baseline, 2 months and 6 months were performed by two-way analysis of variance. Comparative tests between the variables at each time point were conducted with paired $t$-tests. Comparison of variables between the two groups (normalized BHR group and remaining BHR group) was performed by one-way analysis of variance, followed by comparisons with unpaired $t$-tests. Multiple, stepwise, linear regression analysis was performed to identify which variables were significant determinants for the resistance to inhaled corticosteroid treatment on BHR. The $\mathrm{p}<0.15$ was used first to identify candidate variables, and then variables were removed from the regression model if the $\mathrm{p}$ value was more than 0.1 . All statistical analyses were performed with the use of a Windowscompatible software program (Stat Flex ver. 5.0, Artech Ltd., Osaka, Japan). A p value of less than 0.05 was considered significant for the results of all statistical analyses. 


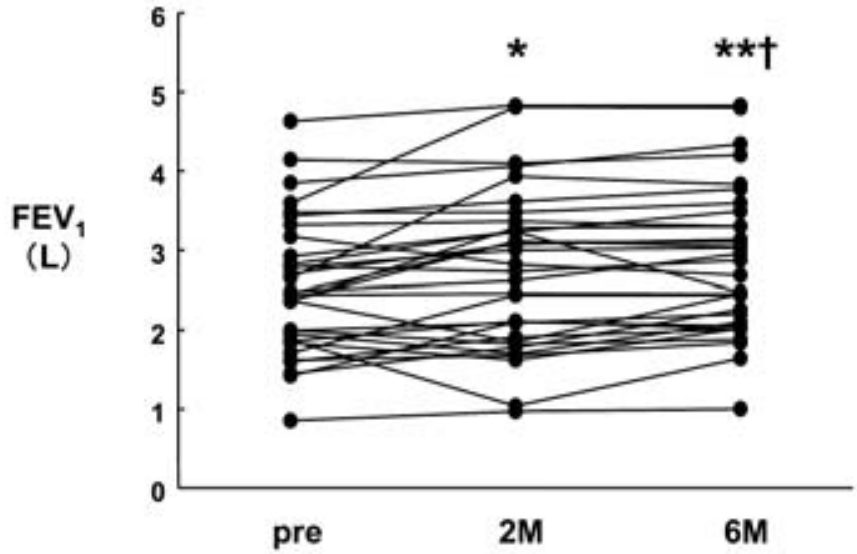

Figure 1. Changes in $\mathrm{FEV}_{1}$ following treatment with $200 \mu \mathrm{g}$ of inhaled fluticasone propionate twice a day for 6 months. $* P<0.05$ and $* * P<0.01$ vs. pre-treatment $\mathrm{FEV}_{1} . \dagger P<0.05$ vs. FEV 1 at 2 months.

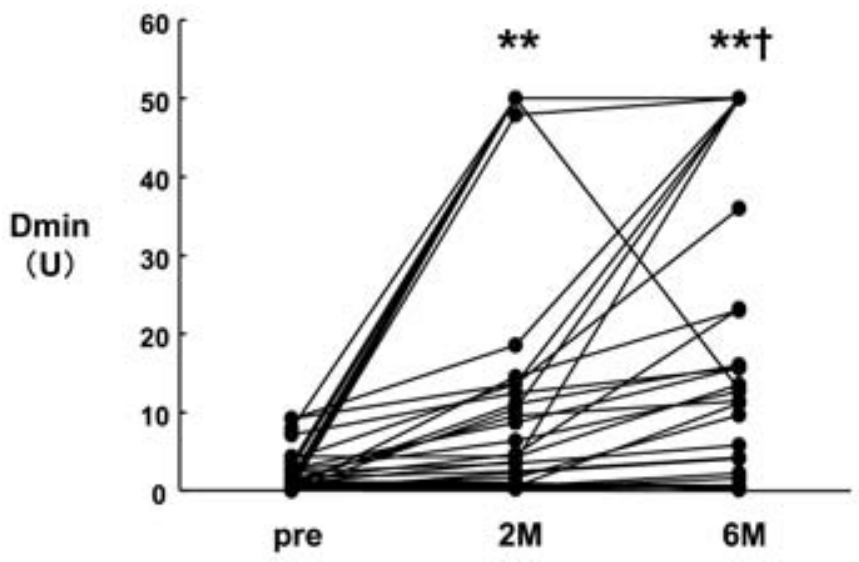

Figure 2. Changes in Dmin following treatment with $200 \mu \mathrm{g}$ of inhaled fluticasone propionate twice a day for 6 months. Airway responsiveness was estimated by the continuous methacholine inhalation method with simultaneous measurement of respiratory resistance ( $R r s)$ using an Astograph. Dmin; cumulative inhaled methacholine dose $(1 \mathrm{Unit}=1 \mathrm{~min}$ of inhalation of $1 \mathrm{mg} / \mathrm{ml}$ methacholine) when $\operatorname{Rrs}$ began to increase. $* * P<0.01$ vs. pre-treatment Dmin. $\dagger P<0.05$ vs. Dmin at 2 months.

\section{Results}

\section{Pulmonary function tests and bronchial respon- siveness}

At baseline measurements (Table 1), 11 patients showed decreases in $\mathrm{FEV}_{1} / \mathrm{FVC}$ of less than $70 \%$, and all patients showed BHR to methacholine. DLco was within the normal range in all patients. Following treatment with $400 \mu \mathrm{g} /$ day of inhaled $\mathrm{FP}, \mathrm{FEV}_{1}$ was increased significantly at 2 months $(2.75 \pm 0.18 \mathrm{~L})$ from baseline $(2.53 \pm 0.15 \mathrm{~L})$, and showed a further significant increase at 6 months $(2.85 \pm 0.16 \mathrm{~L})$

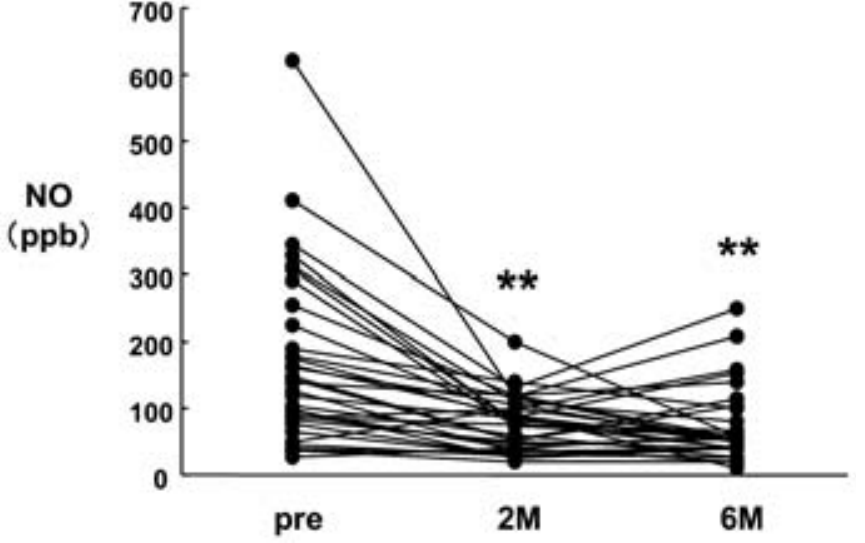

Figure 3. Changes in the concentrations of exhaled nitric oxide (NO) following treatment with $200 \mu \mathrm{g}$ of inhaled fluticasone propionate twice a day for 6 months. $* * P<0.01$ vs. pretreatment exhaled NO.

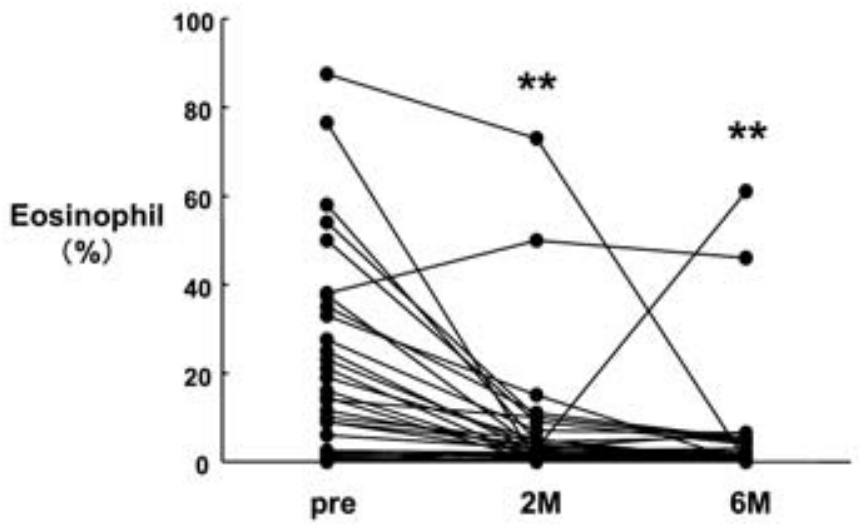

Figure 4. Changes in eosinophil counts in induced sputum following treatment with $200 \mu \mathrm{g}$ of inhaled fluticasone propionate twice a day for 6 months. $* * P<0.01$ vs. pre-treatment eosinophil counts.

(Fig. 1). Following the 6 months of treatment, 8 patients still showed $\mathrm{FEV}_{1} / \mathrm{FVC}<70 \%$. Dmin was increased significantly at 2 months $(17.5 \pm 3.5 \mathrm{U})$ from baseline $(2.1 \pm 0.4 \mathrm{U})$, and showed a further significant increase at 6 months of treatment with inhaled FP $(24.1 \pm 3.6 \mathrm{U})$ (Fig. 2). Dmin values reached within the normal range of more than $12.5 \mathrm{U}$ in 13 and 8 patients at 2 and 6 months, respectively, and these subjects showed improved BHR. However, Dmin remained less than $12.5 \mathrm{U}$ in 13 patients despite 6 months of treatment with inhaled FP.

\section{Exhaled NO and sputum eosinophilia}

The mean concentration of exhaled NO, 166.6 $\pm 22.2 \mathrm{ppb}$, in patients with asthma before treatment with inhaled FP was increased significantly above the normal range in our laboratory (mean $\pm \mathrm{SD} ; 37.4 \pm 8.6 \mathrm{ppb})$. The amount of exhaled NO was decreased significantly at 2 months (76.4 \pm 7.1 ppb) and 6 months (70.4 $\pm 9.3 \mathrm{ppb})$ as compared with baseline values. However, the decrease at 6 months was not sig- 
Table 2. Differences in Normalized AHR and Remaining AHR Groups Following 6 Months of Treatment with $200 \mu \mathrm{g}$ FPbd

\begin{tabular}{|c|c|c|}
\hline & Normalised AHR & Remaining AHR \\
\hline Number & 21 & 13 \\
\hline Male/Female & $9 / 12$ & $11 * / 2$ \\
\hline Age, yr & $47 \pm 4$ & $50.8 \pm 3.8$ \\
\hline Smoking history, n (\%) & $7(33.3)$ & $9(69.2)^{*}$ \\
\hline \multicolumn{3}{|l|}{ Baseline } \\
\hline $\mathrm{FEV}_{1}, \%$ of pred. & $91.5 \pm 2.7$ & $75.3 \pm 4.7 \cdots$ \\
\hline FEV $_{1} \%, \%$ & $77.9 \pm 2.0$ & $70.6 \pm 3.1$ \\
\hline Sputum eosinophils, \% & $18.5 \pm 4.7$ & $23.7 \pm 7.0$ \\
\hline eNO, ppb & $135.0 \pm 19.6$ & $217.6 \pm 46.4$ \\
\hline Dmin, $\mathbf{U}$ & $2.96 \pm 0.65$ & $0.79 \pm 0.19$ \\
\hline \multicolumn{3}{|c|}{ At 6 months following ICS-treatment } \\
\hline $\mathrm{FEV}_{1}, \%$ of pred. & $102.2 \pm 3.0$ & $83.4 \pm 5.2 \cdots$ \\
\hline $\mathrm{FEV}_{1} \%, \%$ & $82.4 \pm 1.7$ & $68.6 \pm 3.6 \cdots$ \\
\hline Sputum eosinophils, \% & $1.3 \pm 0.4$ & $10.5 \pm 5.4^{*}$ \\
\hline eNO, ppb & $65.4 \pm 12.5$ & $78.3 \pm 14.0$ \\
\hline Dmin, $\mathbf{U}$ & $36.6 \pm 3.6$ & $4.0 \pm 1.2 \cdots$ \\
\hline Duration of illness, months & $23.7 \pm 9.4$ & $73.3 \pm 17.8^{\circ}$ \\
\hline
\end{tabular}

nificantly different from the value at 2 months (Fig. 3). Cell analysis of induced sputum obtained before treatment with inhaled FP showed increased relative eosinophil counts. The eosinophil counts were decreased significantly at 2 months $(6.9 \pm 2.5 \%)$ and showed a tendency toward a further decrease at 6 months $(4.8 \pm 2.2 \%)$ from the baseline $(20.5 \pm$ $3.9 \%$ ) (Fig. 4).

\section{Characteristics of asthma patients whose bron- chial responsiveness was still increased despite 6 months of treatment with inhaled FP}

The values of Dmin in 13 patients with asthma were not increased over $12.5 \mathrm{U}$ despite 6 months of treatment with inhaled FP at $400 \mu \mathrm{g}$, and they still showed increased bronchial responsiveness to methacholine (remaining BHR group), and were resistant to a moderate dose of ICS treatment for BHR. In the remaining BHR group, 6 patients still sometimes complained of wheezing in the morning and/or at night or showed variability of peak expiratory flow rate (PEFR). The remaining BHR group showed a significantly greater prevalence of males and subjects with a smoking history, while the values of $\mathrm{FEV}_{1}$ (\% of predicted values) before and 6 months after ICS-treatment and $\mathrm{FEV}_{1} / \mathrm{FVC}$ at 6 months after commencement of treatment were significantly lower as compared with the 21 patients who showed improvement in BHR by 6 months of treatment (normalised BHR group) (Table 2). In six patients in the remaining BHR group, $\mathrm{FEV}_{1} / \mathrm{FVC}$ was still $<70 \%$ and 4 still had a few symptoms or variability of PEFR, whereas only 2 patients in the normalized BHR group showed $\mathrm{FEV}_{1} / \mathrm{FVC}<70 \%$. Furthermore, the numbers of eosinophils in induced sputum from the patients in the remaining BHR group at 6 months after commencement of ICS treatment were significantly higher than those in the normalized BHR group, whereas there was no significant difference in eosinophils at baseline and in the concentration of exhaled NO both at baseline and at 6 months after commencement of treatment. There was no significant difference in the values of Dmin at baseline between the two groups. The duration of asthma history until the first treatment with ICS in the remaining BHR group was significantly longer than that in the normalized BHR group. Multiple, stepwise, linear regression analysis was performed on Dmin following 6 months of ICS treatment among variables including smoking history, Dmin at baseline, duration of asthma history, spirometry, sputum cell analysis, eNO both at baseline and 6 months after commencement of the treatment. The regression model for lower values of Dmin following 6 months of ICS treatment was significant $(r=0.63, p=0.002)$ and comprised the following determinants; eosinophil counts in induced sputum (partial $\mathrm{R}^{2}=0.07, \mathrm{p}=0.10$ ) and lower $\mathrm{FEV}_{1} / \mathrm{FVC}$ (partial $\mathrm{R}^{2}=0.27, \mathrm{p}=$ 0.017 ) following 6 months of ICS treatment and a longer history of asthma until the first treatment with ICS (partial $\mathrm{R}^{2}=0.16, \mathrm{p}=0.049$ ). This model accounted for $33.9 \%$ of Dmin following 6 months of ICS treatment.

\section{Discussion}

In this study, treatment with $200 \mu \mathrm{g}$ of inhaled fluticasone propionate twice a day for 6 months resulted in a significant increase in $\mathrm{FEV}_{1}$, improvement of BHR and a decrease in exhaled NO and eosinophils in induced sputum in 34 symptomatic patients with mild to moderate asthma who had never received any ICS from the onset of asthma. However, BHR failed to normalize in 13 patients treated with ICS added to previous treatments for 6 months. These patients showed a higher prevalence of males associated with a smoking history and persistent airflow limitation, higher eosinophil counts in sputum following ICS treatment for 6 months, and a longer duration of asthma history. Multiple, stepwise, linear regression analysis revealed that sputum eosinophilia and lower $\mathrm{FEV}_{1} / \mathrm{FVC}$ following 6 months of treatment and a longer history of asthma were significant independent determinants for BHR 6 months after ICS treat- 
ment. These findings suggest that the resistance to a moderate dose of ICS for BHR in these asthmatics may be significantly associated with persistent airflow limitation, eosinophilic airway inflammation resistant to a moderate dose of ICS, and the delayed introduction of ICS therapy.

The eosinophil counts in sputum following 6 months of treatment were significantly higher in the remaining BHR group compared with those in the normalized BHR group. BHR to methacholine is closely related to airway inflammation $(18,19)$, and the improvement in BHR may be closely associated with the reduction of airway allergic inflammation, which is reflected by the reduction in eosinophil count with ICS treatment. Therefore, in asthmatics of the remaining BHR group, the 6 months of inhaled FP treatment at the moderate dose of $400 \mu \mathrm{g} /$ day could not induce a sufficient improvement in the eosinophilic airway inflammation, which might be considered to result in poor improvement in BHR. Exhaled NO has been shown to be a marker of airway eosinophilia $(10,11)$, and to decrease following treatment with ICS (20). In the present study, exhaled NO fell rapidly following 2 months of treatment with FP without further improvement at 6 months. However, there was no significant difference in the level of exhaled NO following 6 months of treatment between the normalized BHR group and the remaining BHR group, and the reduction of exhaled NO was not consistent with the improvement in BHR following ICS treatment. Recent studies have demonstrated that exhaled NO levels may not accurately reflect airway inflammation in ICS-treated patients $(21,22)$. The levels of exhaled NO in steroid-naïve asthmatic subjects fall rapidly following ICS intervention, even with low-dose therapy, and prospective studies have not consistently correlated reductions in exhaled NO levels with changes in eosinophil numbers or improvements in BHR.

Overbeek et al (23) demonstrated that a delayed introduction of ICS of 2.5 years in asthmatics leads to less improvement in $\mathrm{PC}_{20}$ although similar improvements were observed in $\mathrm{FEV}_{1}$. In the START trial (24), mild to moderate symptomatic asthma patients who had never been treated with ICS were given ICS for 2 years. A significant negative correlation was found between the duration of symptoms and maximum increases in peak expiratory flow rate or $\mathrm{FEV}_{1}$, and a 2-year delay in treatment with ICS significantly reduced the expected improvement in airway function. It has been suggested that the greatest benefits are achieved if treatment with ICS is started within 2 years of symptom onset $(7,25)$. In the present study, 13 patients in whom BHR did not normalize despite treatment with $400 \mu \mathrm{g} /$ day of ICS for 6 months had a longer duration of asthma history until introduction of ICS ( $>2$ years in 10 of 13 patients). The delayed introduction of ICS therapy from onset of asthma was an important factor for poor improvement in BHR by the treatment with a moderate dose of ICS in mild to moderate asthma. In addition, $\mathrm{FEV}_{1} / \mathrm{FVC}$ remained lower than $70 \%$ following ICS treatment in 6 of these 13 patients, and the inhalation of a $\beta_{2}$-agonist also could not increase their $\mathrm{FEV}_{1} /$
FVC over $70 \%$ (data not shown), suggesting the possibility of the presence of fixed airflow limitation. Eosinophilic airway inflammation also remained to a greater extent as compared with that in the normalized BHR group. Airway remodeling is a possible mechanism for the development of fixed airflow limitation that is observed in chronic asthma patients $(26)$. Ward et al $(27,28)$ have demonstrated that airway inflammation, airway remodeling, and BHR in asthma are inter-related and $40 \%$ of variation in BHR was predicted from the thickness of the reticular basement membrane (RBM), one of histological change in airway remodeling, and airway inflammation. Not only airway inflammation and BHR but also the thickness of RBM will be able to be improved by a long-standing ICS therapy. However, hypertrophy of the airway smooth muscle and fibrosis changes of RBM, which cause fixed airflow limitation, are irreversible structural changes even with a long-standing ICS therapy, which has been suggested to be caused by poor control of asthma for a long time and insufficient anti-inflammatory therapy, ICS, for asthma (29). In this study, multiple regression analysis showed that $33.9 \%$ of variation in BHR evaluated by Dmin was explained by a significant regression model comprised of persistent sputum eosinophilia and airflow limitation following 6 months of ICS treatment and the duration of asthma history up to the first treatment with ICS. Because some patients in the remaining BHR group still showed some symptoms or variability of PEFR, the dose of $400 \mu \mathrm{g} /$ day of fluticasone may be insufficient to improve their BHR and airway inflammation. However, delayed introduction of ICS therapy may also lead to the development of airway remodeling, resulting in remaining airflow limitation, which is one contributing factor for poor improvement in BHR, together with the remaining eosinophilic airway inflammation. Therefore, early intervention with sufficient ICS therapy is very important to improve not only symptoms and pulmonary function but also BHR in its earlier stage and to prevent the development of airway remodeling.

In the present study, the prevalence of a smoking history was significantly greater in remaining BHR group as compared with the normalized BHR group. It was demonstrated that neither lung functions nor eosinophil markers changed in smokers with asthma even following treatment with highdose budesonide (1,600 $\mu \mathrm{g} / \mathrm{day})(30)$, and that current smokers have more asthma symptoms, more frequent asthma attacks and higher asthma severity scores as compared to those who have never smoked and ex-smokers (31). Most of the subjects having a smoking history were ex-smokers and only 3 asthmatics in the normalized BHR group and 2 asthmatics in the remaining BHR group were current smokers. We could not completely exclude the complication of chronic obstructive pulmonary disease (COPD), however, no low attenuation area on chest high-resolution computed tomography (HRCT) could be found. Although multiple regression analysis did not show the smoking history to be a significant predicted factor, smoking history may contribute 
to the poor improvement in eosinophilic inflammation and BHR in response to ICS therapy.

In conclusion, poor improvements in BHR, airflow limitation and eosinophilic airway inflammation in response to treatment with a moderate dose of ICS may be associated with delayed introduction of ICS therapy in asthma. Early intervention with a sufficient dose of ICS in asthma is important to obtain good asthma control.

\section{References}

1. Laitinen LA, Leitinen A, Haahtela T. Airway mucosal inflammation even in patients with newly diagnosed asthma. Am Rev Respir Dis 147: 697-704, 1993.

2. Boulet LP, Bélanger M, Carrier G. Airway responsiveness and bronchial-wall thickness in asthma with or without fixed airflow obstruction. Am J Respir Crit Care Med 152: 865-871, 1995.

3. Lange P, Parner J, Vestbo J, Schnohr P, Jensen G. A 15-year follow-up study of ventilatory function in adults with asthma. $\mathrm{N}$ Engl J Med 339: 1194-1200, 1998.

4. Kerstjens HA, Brand PL, Hughes MD, et al. A comparison of bronchodilator therapy with or without inhaled corticosteroid therapy for obstructive airway disease. N Engl J Med 327: 1413-1419, 1992.

5. Haahtela T, Järvinen M, Kava T, et al. Effects of reducing or discontinuing inhaled budesonide in patients with mild asthma. N Engl J Med 331: 700-705, 1994.

6. Suissa S, Ernst P, Benayoun S, Baltzan M, Cai B. Low-dose inhaled corticosteroids and the prevention of death from asthma. $\mathrm{N}$ Engl J Med 343: 332-336, 2000.

7. Haahtela T, Järvinen M, Kava T, et al. Comparison of a beta 2agonist, terbutaline with an inhaled corticosteroid, budesonide in newly detected asthma. N Engl J Med 325: 388-392, 1991.

8. Pauwels RA, Pedersen S, Busse WW, et al. Early intervention with budesonide in mild persistent asthma: a randomized, doubleblind trial. Lancet 361: 1071-1076, 2003.

9. Global Initiative for Asthma (GINA). Global Strategy for Asthma Management and Prevention: Workshop Report. Update 2005. http://www.ginasthma.com.

10. Smith AD, Cowan JO, Filsell S, et al. Diagnosing asthma. Comparisons between exhaled nitric oxide measurements and conventional tests. Am J Respir Crit Care Med 169: 473-478, 2004.

11. Payne DN, Adcock IM, Wilson NM, Oates T, Scallan M, Bush A. Relationship between exhaled nitric oxide and mucosal eosinophilic inflammation in children with difficult asthma, after treatment with oral prednisolone. Am J Respir Crit Care Med 164: 1376-1381, 2001.

12. Jones SL, Kittelson J, Cowan JO, et al. The predictive value of exhaled nitric oxide measurements in assessing changes in asthma control. Am J Respir Crit Care Med 164: 738-743, 2001.

13. Takishima T, Hida W, Sasaki H, Suzuki S, Sasaki T. Directwriting recorder of the dose-response curves of the airway to methacholine. Chest 80: 600-606, 1981.

14. Mochizuki H, Shigeta M, Kato M, Maeda S, Shimizu T, Morikawa A. Age-related changes in bronchial hyperreactivity to methacholine in asthmatic children. Am J Respir Crit Care Med 152: 906-910, 1995.

15. Fujimoto K, Kubo K, Yamamoto $H$, Yamaguchi $S$, Matsuzawa $Y$. Eosinophilic inflammation in the airway is related to glucocorticoid reversibility in patients with pulmonary emphysema. Chest 115: 697-702, 1999.

16. Kondo R, Haniuda M, Yamanda T, et al. Effects of expiratory pressure on nitric oxide in exhaled breath. Is exhaled nitric oxide really unaffected by pressure? Respir Physiol Neurobiol 139: 3340, 2003.
17. American Thoracic Society. Recommendations for standardized procedures for the on-line and off-line measurement of exhaled lower respiratory nitric oxide and nasal nitric oxide in adults and children. Am J Respir Crit Care Med 160: 2104-2117, 1999.

18. Sont JK, Willems LN, Bel EH, et al. Clinical control and histopathologic outcome of asthma when using airway hyperresponsiveness as an additional guide to long-term treatment: the AMPUL Study Group. Am J Respir Crit Care Med 159: 1043-1051, 1999.

19. Wilson AM, Lipworth BJ. Dose-response evaluation of the therapeutic index for inhaled budesonide in patients with mild-tomoderate asthma. Am J Med 108: 269-275, 2000.

20. Kharitonov SA, Yates DH, Barnes PJ. Inhaled glucocorticoids decrease nitric oxide in exhaled air of asthmatic patients. Am J Respir Crit Care Med 153: 454-457, 1996.

21. Lim S, Jatakanon A, Meah S, Oates T, Chung KF, Barnes PJ. Relationship between exhaled nitric oxide and mucosal eosinophilic inflammation in mild to moderately severe asthma. Thorax 55: 184-188, 2000.

22. Van Rensen EL, Straathof KC, Veselic-Charvat MA, Zwinderman AH, Bel EH, Sterk PJ. Effect of inhaled steroids on airway hyperresponsiveness, sputum eosinophils, and exhaled nitric oxide levels in patients with asthma. Thorax 54: 403-408, 1999.

23. Overbeek SE, Kerstjens HAM, Bogaard JM, Mulder PGH, Dutch CNSLD Study Group. Is delayed introduction of inhaled corticosteroids harmful in patients with obstructive airways disease (asthma and COPD)? Chest 110: 35-41, 1996.

24. Sheffer AL, Silverman M, Woolcock AJ, Diaz PV, Lindberg B, Lindmark B. Long-term safety of once-daily budesonide in patients with early-onset mild persistent asthma: results of the Inhaled Steroid Treatment as Regular Therapy in Early Asthma (START) study. Ann Allergy Asthma Immunol 94: 48-54, 2005.

25. Selroos O, Pietinalho A, Löfroos AB, Riska H. Effect of early vs late intervention with inhaled corticosteroid in asthma. Chest $\mathbf{1 0 8}$ : 1228-1234, 1995.

26. Bousquet J, Jeffery PK, Busse WW, Johnson M, Vignola AM. Asthma. From bronchoconstriction to airways inflammation and remodeling. Am J Respir Crit Care Med 161: 1720-1745, 2000.

27. Ward C, Paris M, Bish R, et al. Airway inflammation, basement membrane thickening and bronchial hyperresponsiveness in asthma. Thorax 57: 309-316, 2002.

28. Ward C, Reid DW, Orsida BE, et al. Inter-relationships between airway inflammation, reticular basement membrane thickening and bronchial hyper-reactivity to methacholine in asthma; a systemic bronchoalveolar lavage and airway biopsy analysis. Clin Exp Allergy 35: 1565-1571, 2005.

29. Elias JA. Airway remodeling in asthma. Unanswered questions. Am J Respir Crit Care Med 161: S168-S171, 2000.

30. Pedersen B, Dahl R, Karlström R, Peterson CGB, Venge $P$. Eosinophil and neutrophil activity in asthma in a one-year trial with inhaled budesonide. The impact of smoking. Am J Respir Crit Care Med 153: 1519-1529, 1996.

31. Siroux V, Pin I, Oryszczyn MP, Le Moual N, Kauffmann F. Relationships of active smoking to asthma and asthma severity in the EGEA study. Eur Respir J 15: 470-477, 2000.

(C) 2006 The Japanese Society of Internal Medicine http://www.naika.or.jp/imindex.html 